\title{
El Padre Ellacuría sobre Monseñor Romero. Ayudas para poner a producir en las iglesias la herencia de Jesús
}

\author{
Jon Sobrino, \\ Centro de Reflexión Teológica, \\ San Salvador.
}

Durante el XXV aniversario de Monseñor Romero, me han venido a la mente varias palabras del Padre Ellacuría sobre él, lapidarias, luminosas, animantes. Con ellas, Ellacuría presentaba a Monseñor como un gran testigo de Jesús, de su vida y destino, de su palabra y obra. Por eso, cuando en este Congreso me pidieron hablar sobre Jesús, se me ocurrió hacerlo de la siguiente manera: presentar a Jesús a partir de Monseñor Romero - su testigo-, tal como Ellacuría vio a Monseñor.

Este modo de proceder puede parecer excesivamente complicado: de Ellacuría a Romero, y de Romero a Jesús. Pero algo importante tiene a su favor. Los testigos y los mártires son quienes mejor conocen y hacen presente al testigo y mártir Jesús. Lo que Ellacuría y Romero vieron en él, y sobre todo, el modo cómo Monseñor lo hizo presente entre nosotros, ofrecen lo que podemos llamar una "cristología de testigos", lo que no hace superflua, obviamente, "una cristrología de textos". Pensamos, sin embargo, que ésta, si no va acompañada, de alguna manera, de aquélla, siempre tiene el peligro de convertirse en cristología excesivamente conceptual, sin realidad suficiente que ponga carne histórica a nuestros pensamientos sobre Jesucristo. Puede degenerar, aunque sea sutilmente, en una "cristología barata"'.

Reflexionar sobre Jesús desde Romero y Ellacuría nos parece importante, pero más importante es que Jesús, Monseñor Romero y el Padre Ellacuría ilumi-

1. Entre ambos tipos de cristología hay un círculo hermenéutico. Para poder afirmar de alguien que es hoy "testigo" de Jesús, hay que remitirse a algún "texto" sobre Jesús, para que no sea la pura imaginación o la pura voluntad la que dirija el discurso. Pero, 
nen y animen a dar solución a algunos problemas actuales de la Iglesia. Entre nosotros, creo que los describen bien estas palabras de don Pedro Casaldáliga:

- "de la misma fe cristiana se está haciendo un recetario de milagros y prosperidades, refugio espiritualista ante el mal y el sufrimiento y un substitutivo de la corresponsabilidad, personal y comunitaria, en la transformación de la sociedad"2.

Esta luz y este ánimo queremos buscarlos alrededor de los siguientes puntos, que eran fundamentales en tiempo de Monseñor, y que hoy no son tan tenidos en cuenta: la centralidad del pueblo, sin pasarlo rápidamente por alto, en nombre del pueblo de Dios; la transcendencia de Dios, que la Iglesia tiene que hacer presente cristianamenre como trans-descendencia y con-descendencia; el seguimiento de Jesús como superación del "docetismo" - perenne tentación de la Iglesia- y de la "irrealidad" en que puede caer la fe; y la apertura a la gracia, la bondad y la santidad, que carga con nosotros, y que puede quedar como escondida y hasta suplantada por medios demasiado mundanos, al llevar a cabo la misión de la Iglesia.

En cada apartado formularemos una breve proposición, que la desarrollaremos en dos partes. En la primera, más larga, recordaremos algunas frases de Ignacio Ellacuría sobre Monseñor Romero. En la segunda, más breve, recordaremos algunas palabras de Jesús. En ambos casos, en relación con cada uno de los temas.

\section{El pueblo}

Primera proposición. La Iglesia debe tomar en cuenta, seria y unificadamente, al "pueblo" y al "pueblo de Dios" de modo que no hable de "pueblo de Dios" sin pueblo, ni de "pueblo" que no esté abierto al "pueblo de Dios".

\section{1. "Difícil hablar de Monseñor Romero sin verse forzado a hablar del pueblo"}

Comenzamos por el tema de "pueblo", pues hoy no suele ser muy tenido en cuenta, en la Iglesia. Sin embargo, además de su intrínseca importancia eclesial y teológica, tenerlo en cuenta puede ser muy útil y necesario para impregnar de realidad, y que no queden evaporados, otros temas más específicamente cristianos, como los que analizaremos en los apartados siguientes: la transcendencia de Dios, el seguimiento de Jesús, y la gracia. Así veía Ellacuría lo que significaba el pueblo para Monseñor. Comenzamos con este texto programático:

a la inversa, para comprender lo que dicen los textos del pasado - y sobre todo el peso real que tienen los conceptos-, se necesita verlos hechos realidad de alguna manera. Textos del pasado y realidades en el presente se iluminan mutuamente.

2. "Del desencanto inmediatista a la utopía esperanzada", Concilium 311 (2005) 156.

3. "El verdadero pueblo de Dios según Monseñor Romero", ECA 392 (1981) 530. 
Sobre dos pilares apoyaba Monseñor Romero su esperanza: un pilar histórico, que era su conocimiento del pueblo al que él atribuía una capacidad de encontrar salidas a las dificultades más graves, y un pilar transcendente, que era su persuasión de que últimamente Dios era un Dios de vida y no de muerte, que lo último de la realidad es el bien y no el mal ${ }^{4}$.

No se puede decir con más claridad la importancia que Monseñor Romero daba al pueblo: era pilar, junto con Dios, de su esperanza. Esa centralidad del "pueblo" no suele ser hoy nada frecuente, y por ello, hay que recordarla. Ellacuría, como Monseñor Romero, conocía el lenguaje que normalmente se usa en el mundo eclesiástico, cuando éste tiene que referirse al pueblo: "sociedad civil", "ciudadanos", o, dentro ya de la realidad eclesial, "laicos", "seglares" - con lo cual ocurre que ese "pueblo" del que quiere hablar no suele ser aquello a lo que todo el mundo llama "pueblo": los seres humanos, inmensas mayorías, organizadas o no, que viven y mal viven, con santidad y pecado, pobres que no dan la vida por supuesto, y cuyo mayor anhelo es la vida. Antes, en tiempos de represión, se añadía que su futuro más probable era algún tipo de muerte, la muerte lenta de la pobreza y del hambre, de la indignidad y de su cultura, y la muerte violenta de la represión ${ }^{5}$.

Pues bien, a ese "pueblo" - todavía "sin añadidos"- no por ser santo y perfecto, con limitaciones y pecados, y ciertamente, acorralado, oprimido, reprimido, y despreciado, amó Monseñor, y a su salvación dedicó su vida, humana, cristiana y sacerdotal. "El que esté en conflictos con el pueblo sí estará en conflictos conmigo. Pero mi amor es el pueblo" (Homilía del 20 de agosto de 1978).

Aun sin mencionar explícitamente al "pueblo", el pueblo era el referente real de muchas cosas, que decía en sus homilías. Lo era, ciertamente, de la denuncia pofética, como defensa del pueblo: "No me cansaré de denunciar el atropello por capturas arbitrarias, por desaparecimientos, por torturas" (Homilía del 24 de julio de 1979), profecía que se concentraba en la denuncia de la injusta riqueza: "Yo denuncio sobre todo la absolutización de la riqueza. Este es el gran mal de El Salvador" (Homilía del 12 de agosto de 1978), y de la mentira: "Estamos en un mundo de mentiras, donde nadie cree ya en nada" (Homilía del 18 de marzo de 1979).

Y el pueblo era también el referente de lo positivo de su mensaje, de su esperanza: "Sobre estas ruinas brillará la gloria del Señor" (Homilía del 7 de

4. "La UCA ante el doctorado concedido a Monseñor Romero", ECA 437 (1989) 174.

5. En otros lugares persiste la muerte por guerras, barbarie y terrorismo. Entre nosotros siguen las muertes por la violencia. Cada día hay en El Salvador 10 homicidios, y 17 en Guatemala. Las causas son diversas a las de épocas pasadas. La más novedosa es la violencia juvenil, las pandillas. La conclusión es que entre el pueblo sigue presente, mayoritariamente, la muerte. 
enero de 1979); de su fe: "la gloria de Dios es que el pobre viva" (Discurso de Lovaina, 2 de febrero de 1980).

A Ellacuría le impactó que el "pueblo" fuese referente esencial para Monseñor. Vio a Monseñor Romero real e incondicionalmente encarnado en el pueblo, encarnación que significó, por un lado, dar al pueblo todo lo que él era y tenía, y, por otro, recibir del pueblo lo mejor que éste tenía. En cualquier caso, Ellacuría vio a Romero correr la misma suerte del pueblo, en el sentido literal de la palabra. "Esa encarnación le ganó el amor del pueblo oprimido y el odio del opresor. Le ganó la persecución, la misma persecución que sufría su pueblo. Así murió y por eso le mataron"6. Y recordemos que "pueblo" significa aquí pueblo todavía "sin añadidos"?.

Pero a Ellacuría le impactó también cómo Monseñor vio la realidad de ese pueblo desde lo específico de la fe cristiana. Y por cierto, en esa forma de ver al pueblo, coincidieron ambos de manera soprendente, sin atreverme a decir quién influyó - teórica y conceptualmente - sobre quién. El hecho es que desde 1977 a 1981, ambos desarrollaron una teología del "pueblo". En ella era fundamental ver al pueblo como fuente de esperanza - como hemos visto- y como portador de salvación - acerca de lo cual diremos una breve palabra más adelante-, pero sobre todo fue central analizar, a la luz de la fe, el hecho y el significado de su sufrimiento. Al pueblo llamaron "pueblo crucificado" y "siervo sufriente de Jahvé".

El 19 de junio de 1977, después de que el ejército se retiró de Aguilares, tras haber asesinado a un gran número de personas, entre cien y doscientas, Monseñor Romero fue a celebrar la eucaristía y se dirigió a los aterrorizados campesinos con estas palabras: "Ustedes son el Divino Traspasado", es decir, los identificó - con todas las analogías del caso- con Cristo crucificado. Y en la semana santa de 1978, lo formuló con toda claridad: "Sentimos en el Cristo de la semana santa, con su cruz a cuestas, que es el pueblo que va cargando también su cruz; sentimos en el Cristo de los brazos abiertos y crucificados al pueblo crucificado" (Homilía del 19 de marzo de 1978). Y en la homilía del 21 de octubre de 1979, identificó al "pueblo" con el "siervo sufriente de Jahvé".

Exactamante lo mismo hizo Ellacuría. Como preparación a Puebla, en febrero de 1978, escribió un largo texto sobre el pueblo sufriente, comparándolo con

6. "Monseñor Romero, un enviado de Dios para salvar a su pueblo", Revista Latinoamericana de Teología 19 (1990) 10. Publicado originalmente en Sal Terrae (diciembre 1980) 825-832.

7. Las palabras que siguen, aunque se relacionan con un caso concreto, pueden comunicar, más allá de toda definición, lo que Monseñor quería decir, cuando hablaba de "pueblo", sin añadidos. "Tenemos que lamentar esta semana también la muerte de dos policías. Son hermanos nuestros. Ante el atropello y la violencia, jamás he parcializado mi voz. Me he puesto, con compasión de Cristo, al lado del muerto, de 
el "siervo sufriente de Jahvé"8. Y pocos años después, en 1981, en un exilio en Madrid, escribió otro famoso texto, en el cual afirma que "el signo de los tiempos" es siempre el pueblo históricamente crucificado". Al llamarlo "signo de los tiempos", decía que es "lo que caracteriza a una época" (cfr. GS 4), y así era con claridad, en aquellos años - aunque Ellacuría añadía audazmente que "siempre" lo es. Pero hay que recordar lo que es menos tenido en cuenta: en el Vaticano II, signo significa también "la presencia de Dios en la historia" (cfr. GS 11). De esa forma, para Ellacuría, el "pueblo crucificado" remite a Cristo crucificado.

Eso ocurría a finales de los años de 1970 , y - en cuanto yo recuerdo - nadie había hablado antes con tal profundidad teológica y cristológica sobre el pueblo. Pero demos un paso más. Tanto Ellacuría como Monseñor Romero tomaron en serio al "pueblo de Dios". Y lo importante, me parece a mí, es que relacionaron las dos cosas, con ganancia para ambas. "El pueblo" otorgaba realismo histórico, creatural al "pueblo de Dios", y a su vez, éste mostraba todo lo que el pueblo podía dar de sí: en el pueblo se volcaba el misterio de Dios, con crítica también, por supuesto, pero, en definitiva, con especial predilección.

Ellacuría le echó mucho pensamiento a esta idea. No cedió, en ninguna de las dos cosas. Su tesis era: ni pueblo de Dios sin "pueblo", ni pueblo que no estuviese abierto a ser pueblo "de Dios". Y en lo que quiero insistir es en que para elaborar esa relación entre ambos se inspiró mucho en Monseñor. En un artículo de $1981^{10}$, describió cuatro características del verdadero pueblo de Dios, tal como él veía que las comprendía Monseñor Romero: "la opción preferencial por los pobres", "la encarnación histórica en las luchas del pueblo por la justicia y la liberación", "la introducción de la levadura cristiana en la lucha por la justicia" y "la persecución por causa del reino de Dios en esa lucha". En esta descripción es claro que están presentes elementos del "pueblo" y del "pueblo de Dios". Se habla, pues, de un "pueblo de Dios", en intrínseca relación con el "pueblo".

la víctima, del que sufre [...]. He dicho que dos policías que mueren, son dos víctimas más de la injusticia de nuestro sistema que denunciaba el domingo pasado. Entre sus crímenes más grandes: lograr confrontar a nuestros pobres. Policías y obreros o campesinos, pertenecen todos a la clase pobre. La maldad del sistema es lograr el enfrentamiento del pobre contra el pobre. Dos policías muertos son dos pobres que han sido víctimas de otros, tal vez pobres también $\mathrm{y}$, en todo caso, son víctimas de ese dios Moloc, insaciable del poder, de dinero, que con tal de mantener sus situaciones no le importa la vida ni del campesino, ni del policía, ni del guardia" (Homilía del 30 de abril de 1978).

8. "El pueblo crucificado, ensayo de soteriología histórica", en CRT, Cruz y resurrección. Presencia y anuncio de una iglesia nueva, México, 1978, pp. 49-82. Después de su asesinato, fue publicado en Revista Latinoamericana de Teología 18 (1989) 305-333.

9. "Discernir el 'signo' de los tiempos", Diakonía 17 (1981) 58.

10. "El verdadero pueblo de Dios según Monseñor Romero", citado en la nota 3. 
Hoy, cuando en la Iglesia y en la sociedad casi no sabemos qué hacer con el pueblo, con la lucha por la justicia y la liberación, hay mucho que meditar, en estas palabras. Y no hay que darlo por descontado. Fue un milagro de aquellos tiempos. Que Ellacuría, el filósofo de la realidad histórica, el teólogo de la liberación, el analista político y mediador de graves conflictos, hablase así no tiene por qué sorprender. Pero que radicalizase ese lenguaje, y los conceptos que están tras él, inspirándose, precisamente, en un arzobispo, un hombre de Iglesia, y por ser hombre de Iglesia, da mucho que pensar, en nuestro tiempo. En Monseñor Romero, veía las formas históricas de configurarse el pueblo como pueblo de Dios. Y de esa manera, cobraba credibilidad lo que pudiera ser el aporte más específico de Monseñor Romero como arzobispo: insertar en esas luchas históricas por la justicia y la liberación la levadura cristiana. Lucha histórica y cristianismo no son fáciles de compaginar. Ese milagro, Ellacuría lo vio realizado en el ministerio de Monseñor Romero.

Digamos también que tanto Ellacuría como Monseñor pusieron nombre al pueblo, y nombre de dignidad. Le llamaron "pueblo crucificado", "divino traspasado", "siervo doliente de Jahvé". Insistimos en ello, y lo valoramos mucho, porque nuestro mundo, sobre todo el occidente de abundancia, con frecuencia, tergiversa la realidad de los pueblos, pero además, en la medida en que le es posible, los ignora y los silencia. En esa situación, poner nombre al pueblo no es cosa pequeña. La grandeza de Monseñor Romero es que puso nombre "divino" al pueblo, sin quitarle su realidad "humana", aunque siempre buscó, por supuesto, corregirla, purificarla, mejorarla. En cualquier caso, no tuvo que "bautizar" al pueblo desde fuera para entregarse totalmente a él. En ningún sentido se hizo verdad en él la ironía de Péguy: "Creen que están en lo eterno porque no están en lo temporal. Como no están con el hombre, creen que están con Dios"11 - y añadimos nosotros: "como no sienten y padecen con el pueblo, piensan que sienten y padecen con el pueblo de Dios". Traemos a colación estas palabras de Péguy, porque son siempre una poderosa llamada de atención para no caer en ese peligro frecuente de los cristianos. Monseñor Romero fue ejemplo insigne de todo lo contrario.

Y dejamos para el final lo que nos parece más sorprendente. Tanto Ellacuría como Monseñor vieron también salvación en ese pueblo. Recordemos que ambos tenían esperanzas en un "pueblo organizado", y que defendieron la necesidad y legitimidad de las organizaciones populares. A ese pueblo organizado animaban y corregían, y en él vieron un potencial de liberación histórica. Baste recordarlo ${ }^{12}$. En lo que ahora queremos concentrarnos es en la salvación que el pueblo puede traer, por ser pueblo sufriente, como los nuestros.

11. Palabras cristianas, Salamanca, 2002, p. 98.

12 .No podemos extendernos ahora sobre el tema. Baste recordar la Tercera Carta Pastoral de Monseñor Romero y Monseñor Rivera, La Iglesia y las organizaciones políticas populares, 6 de agosto de 1978. 
Ellacuría lo afirma con claridad y, por eso, añadió a su texto "el pueblo crucificado" el subtítulo, "ensayo de soteriología histórica". Monseñor Romero no lo conceptualiza en forma tan sistemática, ni cuando habla del tema se deben forzar sus palabras, que en esto, a veces son un tanto tortuosas. Pero pienso que tenía la misma intuición, que solía formular, en lenguaje de la teología tradicional. Pienso que la intuición le venía de la sensibilidad hacia el pueblo y de sus sufrimientos, y de la fascinación que le causaba. Y sobre todo, le venía de su esperanza - contra esperanza e indestrucrtible-, producida por la inmensa bondad que había en el pueblo: "tanto sufrimiento y tanta bondad, no pueden ser en vano". Ese pueblo sufriente es el que, misteriosamente, coopera a la liberación.

En los textos que vamos a citar, Monseñor usa la idea tradicional de que el sufrimiento puede ser redentor, pero la "redención" que puede operar ese sufrimiento no se refiere, en directo, a la redención del pecado, lo cual afirma la teología tradicional, sino a la liberación de la injusticia social. La pobreza real, dice lapidariamente, va a salvar al mundo.

Dios no quiere esa injusticia social... Dios, reclama justicia pero le está diciendo al pobre, como Cristo al oprimido, cargando con su cruz: 'salvarás al mundo si le das con tu dolor no un conformismo que Dios no quiere, sino una inquietud de salvación... acuerpando todo aquello que trata de liberar al pueblo en esta situación" (Homilía del 24 de diciembre de 1979). Bienaventurados los que tienen hambre, bienaventurados los que lloran, bienaventurados los que tiene sed de justicia... es esa pobreza la que va a salvar al mundo (Homilía del 11 de septiembre de 1977).

La tesis de que el pueblo crucificado trae salvación es programática, y hay que historizarla ${ }^{13}$. Pero aunque programática, es de suma importancia mantenerla para no caer en otra tentación innata: la salvación viene de arriba, sea a través de milagros o poderes mundanos - o sólo a través de ciencia, autoridad, jerarquía y liturgia.

\section{2. "Vio mucha gente y sintió compasión de ellos" (Mc 6, 34)}

Si vamos ahora a Jesús no hay que buscar paralelismos fáciles a lo que hemos dicho. No hay muchos textos en los evangelios para ello, y ha cambiado el significado de "pueblo". Sí hay semejanzas con Monseñor, por lo que toca a la denuncia profética de la "opresión", por ejemplo, pero no las hay en apoyar movimientos populares de "liberación". Pero esto no quita que no se pueda decir algo importante de Jesús y su relación con el pueblo, que ofrezca impulsos para que Iglesia y pueblo se encuentren hoy, den y reciban uno del otro.

En los evangelios, el pueblo es referente fundamental de la vida de Jesús. Sin él no se entiende su cotidiano vivir. "Le siguió una gran muchedumbre que

13. Véase lo que escribí en Jesucristo liberador, San Salvador, 1991, pp. 434-439. 
venía de todas partes" (Mc 3, 7). "Le trajeron todos los enfermos y endemoniados. La ciudad entera estaba agolpada a la puerta" (Mc 1, 32s). Tampoco se entienden sus denuncias a los poderosos, que "ponían sobre los hombres cargas intolerables" (Lc 11, 46), y que mientras oprimen a la gente, "se hacen llamar bienhechores" (Lc 22, 25).

Como Monseñor, Jesús se conmovió hondamente ante el sufrimiento del pueblo. "Vio mucha gente y sintió compasión de ellas, pues son como ovejas que no tienen pastor" (Mc 6, 34), "vejados y abatidos", añade Mateo (Mt 9, 36). A ese pueblo de pobres, da esperanza y anuncia la buena noticia del reino (Mc $1,14)$, de modo que, en las tan citadas palabras de J. Jeremias, "el reino pertenece únicamente a los pobres"14. Y, misteriosamente, de ese conglomerado de hambrientos y sedientos, enfermos y desnudos, extranjeros y encarcelados, dice que en ellos está él (el Hijo del Hombre, el rey) presente (Mt 25, 35s). Y aunque sólo sea en un pasaje, al pobre leproso - símbolo del pueblo pobre, oprimido y despreciado-, postrado junto a un ricachón, le pone nombre propio, "Lazáro", no al rico (Lc 16, 20), lo cual no es pequeña cosa, en un mundo que ni los nombra. Esto no quiere decir que Jesús tuviera una visión sistemática de qué era "pueblo" y de qué hacer con él. Pero podemos fijarnos en dos cosas, de las que pueden venir impulsos fructíferos y necesarios hoy.

El primero es que, para Jesús, es esencial la relación con lo que antes hemos llamado "pueblo" sin añadidos. Por ese pueblo, siente honda compasión, a ese pueblo ayuda y acoge, y por defenderlo de sus opresores, muere en cruz ${ }^{15}$. Indudablemente, a Jesús le interesa que ese pueblo sea lo que ahora llamaríamos "pueblo de Dios", y de ahí sus exigencias éticas, que cumpla los mandamientos, sobre todo el del amor, que llega hasta el amor al enemigo, que rece al Padre. Y recordemos lo que proclama a todos: en el ejercicio de la misericordia hacia el "pueblo" sufriente se decide el vivir ya humanamente (Lc 10, 29-37, el samaritano) y el vivir salvadamente (Mt 25, 34.41, el juicio final).

Para la Iglesia es esencial mantener esa relación de Jesús con el pueblo, y el pueblo sufriente. Y no es fácil. La historia muestra que, ya desde muy pronto, con excepciones, la mirada del cristianismo cambió de objetivo, "no se dirigió primero

14. J. Jeremias, Teología del Nuevo Testamento I, Salamanca, 1974, p. 142, cursiva del autor.

15. Se suele discutir cuál fue la respuesta del pueblo a Jesús, sobre todo cuando en algunos pasajes de los evangelios, hacia el final de su vida, el pueblo parece abandonarlo y pide incluso su crucifixión. Las cosas fueron mucho más complejas, como analizo en "El crucificado", en J. J. Tamayo, director, 10 palabras sobre Jesús de Nazaret, Estella, 1999, pp. 320-322. Históricamente, parece válido lo que concluye R. Aguirre: "propiamente Jesús no huye nunca de la gente, sino de las autoridades", en "Jesús y la multitud a la luz del evangelio de Juan", Estudios Eclesiásticos, 218219 (1980) 1071. 
al sufrimiento de la criatura, sino a su culpa"16. En el lenguaje que estamos usando, se fijó más directamente en lo que le dificultaría ser "pueblo de Dios" que en lo que le permitía vivir como "pueblo", creatura de Dios, querido por Dios. Más que por el "pueblo", empezó a interesarse en si era "pueblo de Dios".

El segundo es preguntarnos si en Jesús aparece la dimensión soteriológica, salvífica, del pueblo. Por supuesto, no hay que buscarla como la pensó Ellacuría, por ejemplo, pero aquí nos preguntamos por algo más fundamental: si Jesús vio en las gentes no sólo anhelo de ser salvadas, sino si vio también en ellas salvadores, acciones de salvación para otros, que impactaron al mismo Jesús. Con cierta audacia, nos preguntamos si, en el lenguaje de Puebla, también Jesús fue "evangelizado por los pobres" (n. 1147) y cómo. Es decir, si vio en ellos algo bueno para él.

Sin caer en artificios, recordemos algunos pasajes de los evangelios, que pueden dar indicios de ello. En boca de Jesús se ponen estas palabras: "te doy gracias, Padre, porque han entendido los pequeños y no los sabios" (Mt 11, 25). La exégesis podrá explicar el contexto histórico del hecho y el trasfondo cultural, quizás apocalíptico, de la formulación, pero queda en pie la pregunta que aquí nos interesa: al hablar así, ¿está reconociendo Jesús que algo ha recibido él?, ¿siente gozo en ello? Y podemos preguntar también qué pasaba en Jesús cuando decía al enfermo o a la mujer pecadora, en casa de Simón (sea cual fuere el aporte historizador de Lucas): "vete en paz, tu fe te ha salvado" (Lc 7, 50). ¿Recibía algo Jesús, era agraciado con la fe en Dios de esas gentes pobres, marginadas, sufrientes, pecadoras? ¿Qué pasaba cuando veía a una viuda echar unos centavos en el templo, dando más que los demás (Mc 12, 41-44)? ¿Aprovechaba la ocasión sólo para dar sana doctrina a sus discípulos y zaherir a los ricos, o algo le llegaba a su corazón y a su mente, que lo transformaba? ¿Qué pasaba ante la cananea, quien da la razón a Jesús: "es cierto, Señor", pero que también conmovedoramente lo corrige: "también es cierto que los perros comen las migajas que caen de la mesa de sus amos"? ¿Dijo Jesús solamente, desde arriba, “muy grande es tu fe, mujer” (Mt 15, 28)? ¿O se dijo también a sí mismo, desde dentro - como lo hacía Monseñor-, "con este pueblo no cuesta ser buen pastor, este pueblo mueve a su servicio"?

No hay que caer en anacronismos. Pero estas dos cosas, poner la mirada en el pueblo, en cuanto pueblo, sufriente y esperanzado, y dejarse evangelizar - de alguna manera, en alguna medida - por la gente, son fundamentales. No ocurre con frecuencia en nuestros días, y la Iglesia hará bien en retomarlas, como hacía Monseñor Romero.

16. "Hacia una cristología después de Auschwitz", Selecciones de Teología 158 (2001) 114. Ver también, "La compasión. Un programa universal del cristianismo en la época de pluralismo cultural y religioso", Revista Latinoamericana de Teología 55 (2002) 25-32. 


\section{Dios}

Segunda proposición. La Iglesia debe hacer presente la transcendencia, pero a la manera de trans-descendencia y con-descendencia. Así es su Dios.

\section{1. “Con Monseñor Romero, Dios pasó por El Salvador"}

En una misa que celebró pocos días después del asesinato de Monseñor, el Padre Ellacuría dijo: "con Monseñor Romero, Dios pasó por El Salvador". Vio ese paso de Dios en la totalidad de la vida y destino, hechos y palabras de Monseñor. Ahora voy a concentrarme sólo en las palabras de Monseñor Romero, teniendo en cuenta, sin embargo, que en ellas aparecía -o asomaba - su totalidad. Obviamente, nunca dijo que, por ser palabras suyas, Dios pasaba por El Salvador con ellas. Pero eso es lo que muchos experimentaron -y personalmente, estoy convencido de ello. Fue mérito de Ellacuría captarlo y formularlo.

La transcendencia. Empecemos con algunas palabras de Monseñor más solemnes. En ellas, Dios se hacía presente, por así decirlo, como Dios, en su transcendencia absoluta. Y en esas frases, Monseñor Romero menciona explícitamente a Dios sin añadidos. Ese Dios era a veces el Dios de la denuncia total, implacable, el Dios del "Caín, ¿qué has hecho de tu hermano?" (Gen 4, 9). Así fueron las conocidas palabras finales de su última homilía dominical.

Hermanos, son de nuestro mismo pueblo, matan a sus mismos hermanos campesinos, y ante una orden de matar, que dé un hombre, debe prevalecer la ley de Dios que dice: no matar. Ningún soldado está obligado a obedecer a una orden contra la ley de Dios... En nombre de Dios, pues, y en nombre de este sufrido pueblo, cuyos lamentos llegan hasta el cielo cada día más tumultuosos, les pido, les ruego, les ordeno en nombre de Dios, cese la represión (Homilía del 23 de marzo de 1980).

Otras veces, era el Dios bienaventurado y humanizador, el Dios del "en mí encontrarán fuentes de aguas vivas" (Jer 2,13 ), sin que nada pueda sustituir esa fuente de vida. En una de sus últimas homilías, en medio de la barbarie, se remitió, indefensa y esperanzadamente, a ese Dios, de nuevo sin añadidos: "Ningún hombre se conoce mientras no se haya encontrado con Dios... Quién me diera que el fruto de esta predicación de hoy fuera que cada uno de nosotros, fuéramos a encontrarnos con Dios" (Homilía del 10 de febrero de 1980).

Ellacuría captó muy bien que Monseñor Romero habló de Dios, el misterio insondable, siempre inalcanzable. Y que por ser Dios así, le es inherente humanizar la historia, atraerla hacia sí. Así lo captó y formuló:

Monseñor Romero nunca se cansó de repetir que los procesos políticos, por muy puros e idealistas que sean, no bastan para traer a los hombres la liberación integral. Entendía perfectamente aquel dicho de san Agustín de que para 
ser hombre hay que ser "más" que hombre. Para él, la historia que sólo fuese humana, que sólo pretendiera ser humana, pronto dejaría de serlo. $\mathrm{Ni}$ el hombre ni la historia se bastan a sí mismos. Por eso, no dejaba de llamar a la transcendencia. En casi todas sus homilías salía este tema: la palabra de Dios, la acción de Dios rompiendo los límites de lo humano. Una transcendencia que nunca se presentaba como abandono de lo humano, como huída del hombre, sino como su superación y perfeccionamiento. Un más allá que no abandonaba el más acá sino que lo abría y lo impulsaba hacia adelante ${ }^{17}$.

La trans-descendencia y con-descendencia. A ese Dios transcendente e infinitamente otro, Ellacuría lo vio pasar también, por así decirlo, en la palabra cotidiana de Monseñor. Entonces, era un Dios de un caminar concreto, abajado y acogedor, y su transcendencia se hacía trans-descendencia y con-descendencia. Esto ocurría con muchas palabras de Monseñor, aun con aquellas en que no aparecía la palabra "Dios". Aparecían las características del Dios de Jesús. Cuando hablaba - de cualquier cosa que fuese importante para los seres humanos y el país -, Monseñor siempre comunicaba “algo de Dios". Remitía a Dios, y el pueblo intuía, sin saberlo explicar bien, que era Dios a quien quedaba remitido. Recordemos algunas palabras suyas.

Palabras de seriedad, en medio de la farsa social. "El robar se va haciendo ambiente. Y al que no roba se le llama tonto" (Homilía del 18 de marzo de 1979). "Se juega con los pueblos... Se juega con la dignidad de los hombres" (Homilía del 11 de marzo de 1979). "Estamos en un mundo de mentiras, donde nadie cree ya en nada" (Homilía del 18 de marzo de 1979). Y también - por mantener seriedad ante la realidad - ponía en palabra lo sombrío de la Iglesia: "sería triste una Iglesia que sólo condena, que sólo mira pecados fuera de ella, sin reconocer que también ella es pecadora" (Homilía del 8 de julio de 1979). Y recordaba lo evidente: "predicar es relativamente fácil, pero vivir lo que se predica... Entonces, surgen los conflictos" (Homilía del 16 de julio de 1978). Con estas palabras, Monseñor venía a decir. "Hay que ser serios. Dios no es así. Con Dios no se puede jugar". Y sub specie contrarii, apuntaba a descubrir a Dios, allá donde los seres humanos actúan con honradez y seriedad.

Más conocidas son sus palabras de honradez y verdad, en medio del encubrimiento y la mentira institucionalizada, y por ello, no vamos a repetirlas. Recordemos sólo dos cosas programáticamente. La primera es que, con insobornable libertad, denunciaba también a los responsables de la injusticia, la mentira y la represión, bien fuese el presidente de la república, la Corte Suprema de Justicia, la Asamblea Legislativa, las fuerzas armadas, los cuerpos de seguridad, la oligarquía, el gobierno de Estados Unidos. De esa forma, su denuncia no sólo era ética, que condena males, sino profecía, que denuncia a sus responsables. Tras

17. “Monseñor”, p. 9. 
esas palabras resonaba el Dios que denuncia por nombre con absoluta libertad y más allá de todo posible chantaje: "Caín, Caín".

La segunda es que su denuncia era, ante todo, misericordia hacia las víctimas. Denunciaba todos y cada uno de los hechos de barbarie, pero, además, mencionaba, por principio, los nombres también de las víctimas, y de "todas" las víctimas, añadiendo algún detalle sobre el lugar y las circunstancias, aunque eso alargase sus homilías, hasta llegar, en alguna ocasión, a las dos horas. En esta minuciosidad estaba en juego no sólo, ni principalmente, la necesaria meticulosidad de informes jurídicos, sino algo más profundo: la dignidad de las víctimas. En ese sentido, bien podemos decir de Monseñor que fue iniciador y guardián de la "memoria histórica".

En la homilía del 30 de octubre de 1977, explicó, en cinco puntos, la estructura de sus homilías, en la parte en que recogía los hechos de la semana, que estaba estrucurada según lo que veía como más importante y que más llevaba en el corazón: dar consuelo a las víctimas, repudiar el crimen, apoyar los justos reclamos del pueblo, dar esperanza al pueblo y anunciar la transcendencia de Dios, más alla de todos nuestros proyectos. Todas éstas son cosas de suma importancia, pero todo empezaba con el consuelo, que proviene de la compasión y la misericordia. Tras esas palabras resonaba el Dios del Éxodo, de los profetas y de Jesús, que "escucha los clamores del pueblo sufriente", ofrece consuelo y liberación.

Por último, palabras de humanidad, en medio de la inhumanidad, que siempre comunicaban destellos de la humanidad de Dios. Cercanía: “¡Cómo me da gusto en los pueblecitos humildes que las gentes y los niños se agolpan a uno, vienen a uno!" (Homilía del 12 de agosto de 1979). Afecto: "Para mí son nombres muy queridos: Felipe de Jesús Chacón, 'Polín'. Yo les he llorado de veras" (Homilía del 15 de febrero de 1980). Dignidad: "Ustedes son el divino traspasado" (Homilía del 19 de julio de 1977). Esperanza: "Estoy seguro de que tanta sangre derramada y tanto dolor no será en vano" (Homilía del 27 de enero de 1980). Y todo con humildad: "Yo creo que el obispo siempre tiene que aprender del pueblo" (Homilía del 9 de septiembre 1979), y con credibilidad: "El pastor no quiere seguridad mientras no se la den a su rebaño" (Homilía del 2 de julio de 1979). Y lo más humano, con gozo: "Con este pueblo no cuesta ser buen pastor" (Homilía del 18 de noviembre de 1979). Tras estas palabras resonaba el Dios bueno.

Hoy, hay muchas palabras de los poderes de este mundo, que son quizás más educadas y pulidas que en tiempo de Monseñor. Pero una cosa sigue siendo cierta: Dios no habla así. Y algo parecido hay que decir del lenguaje religioso rutinario: Dios no habla asi. Dios habla como hablaba Monseñor. Y porque hay relación entre palabra y presencia, la palabra de Monseñor Romero hacía que Dios pasase por El Salvador. Y no cualquier Dios, sino aquel que, como gusta de repetir Gustavo Gutiérrez, "del más chiquito tiene memoria". 
En cualquier caso, la de Monseñor siempre fue como "la palabra de Dios, limpia y pura como el agua que baja de los montes", que decía Rutilio Grande. Esa limpieza y pureza también hacían presente a Dios. El lo dijo con palabras parecidas, en tiempos de barbarie: "Dios no camina por allí, sobre charcos de sangre y de torturas. Dios camina sobre caminos limpios de esperanza y de amor" (Homilía del 7 de agosto de 1977). En Monseñor estaba Dios y el pueblo así lo intuía: "Nunca habían sentido a Dios tan cerca... El pueblo se abría a la transcendencia cristiana"18.

\section{2. "Jesús de Nazaret pasó haciendo el bien y curando a todos los oprimi- dos por el diablo, porque Dios estaba con él" (Hech 10, 38)}

No podemos ahora desarrollar este tema central para la fe. Sólo haré dos reflexiones, desde lo que hemos dicho, a propósito del paso de Dios con Monseñor.

La primera es cómo captó la gente la presencia de Dios, en Jesús. Poco después de su crucifixión y resurrección, Jesús de Nazaret fue reconocido como el ser humano por excelencia, el nuevo Adán. Pero fue reconocido también como el ser humano, en el que se hizo presente Dios, "Hijo de Dios", "palabra de Dios", "Señor", en lugar de Dios. Que con Jesús pasó Dios, lo dice bellamente el Nuevo Testamento: "Ha aparecido la benignidad de Dios... Se ha hecho visible la bondad de Dios" (Tit 2, 11; 3, 4). La razón es que si Jesús pasó por este mundo haciendo el bien, es que "Dios estaba con él" (Hech 10, 38). L. Boff lo ha formulado magníficamente: "Así de humano sólo puede ser Dios".

Esto sigue siendo importante, hasta el día de hoy. Lo es para creyentes, evidentemente. Pero lo puede ser también para no creyentes, lo formulen de la forma que sea, pues significa que la realidad, en definitiva, no es absurda, sino que en el fondo de ella hay bondad, salvación. Lo que puede aportar con sencillez y humildad la fe cristiana es que, en Jesús, la trascendencia de Dios se hace trans-descendencia y con-descendencia. Y la consecuencia importante es que confesar esa transcendencia no es cosa sólo de doctrina y liturgia, sino que es cosa de hacer real el abajamiento (tran-descendencia) y la acogida (con-descendencia). Así pasó Dios, en Jesús. La tarea y la responsabilidad para la Iglesia es obvia. Gran ayuda es el modo de Monseñor Romero de hacer presente a Dios, abajándose y acogiendo.

Lo segunda es que, en un mundo que lo ignora o lo trivializa, la fe no sólo confiesa el hecho de la transcendencia, sino que dice que es bueno que haya transcendencia. Es el "más" que atrae y hace que la realidad dé "más" de sí. Es como la reserva de bondad, de verdad y de esperanza, en la historia. Eso se ha dicho de Jesucristo, y Monseñor Romero puede ayudar a comprenderlo. "La necesidad, entonces de algo transcendental, de algo que venga de fuera se hace

18. "Monseñor Romero", pp. 9 y 10. 
sentir" (Homilía del 7 de enero de 1979). Y Ellacuría lo corroboraba, comentando sus homilías: "Una transcendencia que nunca se presentaba como abandono de lo humano, como huída del hombre, sino como su superación y perfeccionamiento. Un más allá que no abandonaba el más acá, sino que lo abría y lo impulsaba hacia adelante"19.

Hoy en día, es importante -y urgente - superar lo romo y superficial, no quedar atrapados en el espíritu de geometría, sino avanzar hacia el espíritu de finura, que decía Pascal. Para ello, bueno es pensar en términos de transcendencia, y hacerla presente, en términos religiosos o seculares. Para la Iglesia es esencial no sólo mencionarla - "es muy fácil hablar de la transcendencia", solía decir Monseñor-, sino hacerla presente y poner gestos reales de que es abajamiento -no pompa y triunfalismo- y acogida - no autoritarismo e imposición.

\section{El seguimiento}

Tercera proposición. El peligro de propiciar o tolerar una fe alienante, que lleva a la evasión -la irresponsabilidad-, y a una fe infantilizante, que lleva a la irrealidad - el docetismo de siempre-, es recurrente en la Iglesia. Para superarlo, es necesario volver al seguimiento de Jesús.

\section{1. "Monseñor Romero fue un seguidor ejemplar de Jesús de Nazaret"20}

Ellacuría vio en Monseñor Romero a un pastor, que defendió a su pueblo, a un profeta, que se enfrentó con los enemigos de ese pueblo y a un mártir, fiel hasta el final al Dios que lo envió a salvar a ese pueblo. Pero siendo esto verdad, quiero recordar unas palabras suyas, menos grandilocuentes, pero más tajantes, que van a la raíz de todo: "Monseñor fue un seguidor ejemplar de Jesús de Nazaret".

Qué de Monseñor Romero le recordó a Jesús, quizás puede concentrarse en estas palabras, que Ellacuría dijo sobre Jesús, en una clase: "Es que Jesús tuvo la justicia para ir hasta el fondo y al mismo tiempo tuvo los ojos y entrañas de misericordia para comprender a los seres humanos... Fue un gran hombre". Esto no dice todo lo que Ellacuría vio en Jesús, pero sí algo que le impactó profundamente. Pues bien, eso es también lo que vio como central en Monseñor Romero: su inmensa compasión ante el sufrimiento del pueblo, la justicia para ir a la raiz de las cosas, y, junto a esto, la esperanza -contra esperanza-, que daba a ese pueblo.

Otras cosas de Monseñor le recordaron a Jesús, por supuesto: su inmensa libertad para decir la verdad a todos, con la cual, en directo, defendía a unos, y

19. "Monseñor", p. 9.

20. Ibid., p. 10. 
exigía conversión radical a otros - también la exigía al pueblo, pero a sus opresores, la exigía con máxima radicalidad - ; su firmeza, en medio de persecuciones, desprecios y malos entendidos, incluso de parte de sus hermanos obispos. Y le impactó su fe en el misterio de un Dios-Padre: Padre, porque en ese Dios descansaba Monseñor; y Dios, porque el Padre nunca lo dejaba descansar ${ }^{21}$.

A Ellacuría, pues, Monseñor le recordó a Jesús de Nazaret. En Monseñor, vio los contenidos fundamentales que veía en Jesús. Esto quiere decir que no sólo vio en él a alguien que predicaba a un Jesús con características específicas, sino a alguien que lo hacía presente. Monseñor Romero remitía a Jesús, pero de una manera determinada: remitía a él, siguiéndolo, haciéndolo real en la historia, sin condiciones. Monseñor Romero fue un gran creyente, por supuesto, pero con prioridad lógica, por así decirlo, fue un gran seguidor.

Este recordatorio nos parece hoy muy necesario. Es importante que la Iglesia proponga contenidos concretos de Jesús, para no inventar - so capa de devociones y apariciones - a un Jesús que no se parece al de Nazaret. Pero, sobre todo, tiene que insistir - y dar ejemplo- en que a ese Jesús se accede, en definitiva, en el seguimiento. Eso es lo que hizo Monseñor Romero. Hizo real en su vida lo que fue la vida real de Jesús, y así hacía que el cristianismo que anunciaba fuese cosa "real", y que la fe en Jesús se expresase en cosas reales, lo cual nunca ha sido obvio y no lo es en nuestros días.

Hoy, en las iglesias hay exceso de triunfalismo y entusiasmo, la búsqueda de éxitos, medidos por números elevados, y expresado con pompa y boato, en ocasiones hasta la apoteosis. Todo ello, nos saca de la realidad de esta humilde creación. Y hay también exceso de infantilización - el cristianismo light, que facilita éxitos aparentes-, de credulidad alienante, que confunde el "hacerse como niños" - sencillos, confiados-, de lo cual hablaba Jesús, con el infantilismo de no pensar, de no ser críticos, de lo cual no hablaba Jesús. Esto aleja de la inseguridad, pero también de la condición humana. Dicho en forma de tesis, pensamos que una fe así cae en irrealidad, como si Dios manejase su historia sin nosotros y a base de milagros. Es el docetismo eclesial. Y no humaniza.

Para superar el peligro de irrealidad, hay que volver al "Jesús histórico", como antes se decía. Y lo más histórico de ese volver es el "seguimiento". No es esto una "marcha atrás", algo obsoleto y voluntarista, como si no se aceptasen los cambios de paradigmas. Es un volver al aliento insustituible del origen, a "ese Jesús histórico que tantas veces se nos difumina en dogmatizaciones helenísticas y en espiritualismos sentimentales, el Jesús pobre, solidario con los pobres, el

21. Sobre esto último, quisiera añadir que, con todo lo indefenso que es hablar de estas cosas, pienso que el Ellacuría pensante, filósofo, crítico, todo menos crédulo, conocedor de los mil y un problemas que tiene en nuestros días depositar fe en un misterio que nos sobrepasa, fue atraído por una fe como la de Romero. Pienso que le fascinaba. 
crucificado con los crucificados de la historia"22. Quizás lo podamos esclarecer en forma de tesis.

El seguimiento nos hace "ser" como Jesús, con lo cual, además, "damos cuerpo" histórico a Jesús y lo "incorporamos" a la historia. Con limitaciones y aun pecados, el seguimiento es lo que anula nuestra exterioridad con respecto a Jesús. Seguidores de Jesús son los que, en la realidad, no sólo en la intención o en la oración, se parecen a Jesús. Según un más y un menos, por supuesto, "son" como Jesús - y por cierto, eso es lo que hemos dicho de los mártires de nuestros pueblos latinoamericanos: son mártires "jesuánicos", porque han vivido como Jesús, han amado al pobre y lo han defendido de sus opresores, han denunciado el pecado de éstos, se han mantenido firmes en la persecución que ello les ha ocasionado, y han acabado en una cruz como Jesús ${ }^{23}$. El seguimiento hace que la fe no quede desleída de su sustancia real ${ }^{24}$.

Por ser cosa real, el seguimiento hace inocultable la dimensión dialéctica, duélica y contracultural de la fe cristiana, lo cual, comprensiblemente, se tiende a ignorar con facilidad. La fe es "una victoria" (1Jn 5, 4). Y es en el proceso real de seguir a Jesús, no en la mera intencionalidad, donde aparece contra qué hay que luchar y qué batalla hay que vencer: la duda, el desencanto, la tentación del carpe diem, la persecución, el comprensible miedo y la tentación al abandono, el "no lo conozco" de Pedro, los costos del "toma tu cruz" que exige Jesús... La fe en Jesús no es entonces sólo aceptación de verdades sobre Cristo, todo lo sublimes que se quiera, ni s6́lo el ejercicio de virtudes, todo lo legítimo y necesario que se quiera, sino la entrega real y verdadera de la persona al misterio de Dios, que se engrandece y empequeñece, se esclarece y se oscurece, en el seguimiento de Jesús. Y es la lucha contra el mysterium iniquitatis, los ídolos y las fuerzas del antirreino. La fe en Jesús es entonces victoria, no sólo pacífica aceptación de verdades, reales o supuestas, ni sólo un bienaventurado sentimiento de acogida, por parte de la divinidad.

22. Pedro Casaldáliga, "Carta abierta al hermano Romero", Revista Latinoamericana de Teología 64 (2005) 4.

23. "Los mártires jesuánicos en el tercer mundo", Revista Latinoamericana de Teología 48 (1999) 241-246.

24. Proseguir a Jesús es "rehacer realidades". Si se me permite usar lenguaje zubiriano, no sé si muy adecuadamente, el homo religiosus es homo religatus, pero, por ser homo, sigue siendo animal de realidades: va a Dios, yendo a Dios. Y se relaciona con Dios, cargando en la historia con realidades de Dios. "El acto o los actos de acceso del hombre a Dios no son los formalmente intelectivos, sino que son aquellos que física y realmente nos llevan efectivamente a $\mathrm{El}$ en tanto realidad absoutamente absoluta" (X. Zubiri, El hombre y Dios, Madrid, 1984, p. 181). ¡Qué bien se echaba esto de ver en Monseñor Romero! 
Digamos también que el seguimiento es principio epistemologico para dar el salto de la fe. En el seguimiento se da la afinidad necesaria para saber quién es ese Jesús, a quien confesamos como el Cristo e Hijo de Dios. Fuera del seguimiento no sabemos exactamente de qué estamos hablando, cuando hablamos del Cristo. Ni sabemos lo que afirmamos, cuando decimos que tenemos fe; ni sabemos lo que negamos, cuando afirmamos que no la tenemos. Falta el elemento de afinidad. Esa fe llega a ser cosa real dentro del seguimiento real, y luchando contra cosas reales, que entorpecen y obstaculizan el seguimiento. $\mathrm{Y}$ es también dentro del seguimiento donde puede surgir -y surge - el "más" específico de toda fe, el momento de transcendencia. En el seguimiento se va experimentando que la historia va "dando más de sî", o "va dando menos de sî". Se va "abriendo" o se va "cerrando". En él aparece la pregunta por la transcendencia, más desde la razón práctica que desde la razón puramente teórica: si la esperanza es más sensata que la resignación, si el amor mayor de dar la vida es más sensato que el egoísmo de guardársela. Y la respuesta puede ser un sí, en la medida que experimentamos que, en definitiva, la realidad está transida de un misterio mayor, de esperanza y amor.

Es claro que Monseñor "fue" como Jesús, reprodujo sus contenidos y fue su seguidor. Que él mismo interpretase ese seguimiento exactamente con las caracterísricas que acabamos de exponer, no podemos saberlo. Pero algunas cosas sí sabemos, y algunas muy importantes. Monseñor tuvo graves dificultades en el seguimiento de Jesús y acabó como Jesús. El mismo lo reconoció. En su último retiro espiritual, un mes antes de su muerte, menciona a su confesor sus dos problemas más graves: los problemas con sus hermanos obispos y el miedo a la muerte. Su seguimiento fue, pues, como la fe, una "victoria"25. Y de eso, la Iglesia está necesitada para ser una Iglesia real.

\section{2. "Quien quiera venir en pos de mí, niéguese a sí mismo tome su cruz y sígame" (Mc 8, 35)}

El seguimiento es la dificultad especificamente cristiana que tiene la Iglesia, y así ocurrió desde los comienzos. Los primeros cristianos reconocieron pronto a Jesús como “alguien especial". Lo hacían en la eucaristía, entonaban himnos en su honor, y desarrollaron cristologías, a veces llenas de entusiasmo: lo empezaron a llamar "Señor", "Hijo de Dios", "Cabeza de la creación", y tenían la esperanza de su pronta venida. Pero los más lúcidos, pronto vieron los peligros de quedarse sólo en eso y lucharon contra ello. Así lo hizo Pablo, recordando a los carismáticos entusiastas, "irreales" los hemos llamado- de Corinto, que la sabiduría de Dios está en la realidad de una cruz (1Cor 1, 8-23), escándalo y necedad. Se habían olvidado de Jesús, y algunos hasta renegaban de él - como se cuenta de esa

25. "El último retiro espiritual de Monseñor Romero", Revista Latinaomericana de Teología 13 (1988) 6. 
comunidad: "anatema es Jesús", decían algunos (1Cor 12,3)—, porque pensaban que habían encontrado cosas mejores: un vaporoso espíritu.

Y también lo hizo Marcos ${ }^{26}$, en quien me voy a detener un poco más, porque es uno de los ejemplos más preclaros de esa seria advertencia contra la comprensión del cristianismo entusiasta, light, irreal. Con su evangelio, vino a "molestar" a cristianos demasiado complacientes - y tengo ahora en cuenta la coyuntura actual del aniversario de Monseñor Romero para aprender cómo hay que celebrarlo y cómo no hay que celebrarlo.

El evangelio de Marcos celebra a Jesús, pero con grandes cautelas. Lo proclama "Hijo de Dios", pero no pone esta invocación en labios de gente piadosa, sino sólo en labios de demonios (Mc 5,7) y de un pagano, el centurión romano (Mc 15, 39). Y eso ocurre, además, al pie de la cruz ante el cuerpo destrozado de ese Hijo de Dios. También lo llama "Mesías", pero, cuando eso ocurre, el mismo Jesús exige que no lo digan a nadie.

Marcos insiste en que la fe en Jesús no es ni triunfalista, ni light, ni fácil. Es cosa seria, todo menos evidente. No fue fácil, ni para sus familiares, ni para los discípulos - en especial para Pedro-, y ciertamente, no lo fue para los teólogos y sacerdotes de aquel tiempo. Y su evangelio termina abruptamente, en Mc 16, 8, dejando casi más preguntas que respuestas: "las mujeres salieron huyendo del sepulcro, pues un gran temblor y espanto se había apoderado de ellas, y no dijeron nada a nadie porque tenían miedo". Tan chocante fue ese final que, más tarde, se le añadieron unos versículos para amortiguar el susto.

Pues bien, el Jesús que no está interesado en que lo llamen Mesías, sí está interesado en otra cosa: el "seguimiento". En los evangelios, "sígueme" es la primera y última palabra de Jesús a Pedro, como recuerda Bonhoeffer. En Marcos, el mismo Jesús lo dice lapidariamente: "Si alguien quiere venir en pos de mí, niéguese a sí mismo, tome su cruz y sígame" (Mc 8, 34). Jesús llama al seguimiento, y no hay vida cristiana sin responder, en lo sustancial, a esa llamada, que tiene prioridad sobre cualquier otra exigencia institucional.

Y un último aporte de Marcos sobre el seguimiento. En la escena del bautismo se abren los cielos y Jesús escucha las palabras del Padre celestial (Mc 1,11). Es la llamada a su misión desde lo alto, pero históricamente, Jesús prosiguió, de hecho, con su especificidad propia, un camino comenzado por otros. Así lo cuenta Marcos: "Apresado Juan, marchó Jesús a Galilea y proclamaba la Buena Nueva" (Mc 1, 14; Mt 4, 12). Dejando ahora a un lado precisiones exegéticas, se dice aquí que Jesús comenzó su propia misión, relacionándola de algún modo con la de Juan -y parece muy verosímil que así fuese, existencialmente.

26. Cfr. X. Alegre, "Un silencio elocuente o la paradoja del final de Marcos", Revista Latinoamericana de Teología 58 (2003) 3-24. 
En lo concreto de la misión es bien sabido que hay semejanzas y diferencias entre ambos ${ }^{27}$, pero lo que interesa recalcar es la conciencia de Jesús de estar prosiguiendo, en forma nueva y distinta, lo que otros habían hecho antes - el mismo Jesús se considera en relación con los profetas de Israel. Y aparece también esa conciencia en un momento muy importante de su vida. Los discípulos fueron a informarle de la muerte de Juan, "y al oírlo Jesús se retiró de allp” (Mt 14, 13; Mc $6,30)$. Jesús lo sintió como algo premonitorio. Esto significa que el Jesús que llamó al seguimiento, de alguna forma, pasó también por la experiencia de entroncarse en una tradición comenzada por otros, Juan, en este caso, y antes, los profetas de Israel. El cauce por el que caminó no era enteramenrte nuevo, aunque él lo fue configurando, de forma específicamente suya.

Recordar esto, nos parece muy importante para la Iglesia. En años recientes, la Iglesia salvadoreña pasó por momentos de esplendor cristiano. Retomó la tradición fundante del seguimiento de Jesús e historizó un cauce de ese seguimiento. Ese cauce podemos decir que se forjó así: "Asesinado Rutilio Grande, comenzó Monseñor Romero, y asesinado Monseñor Romero comenzó el Padre Ellacuría"28. Rutilio, Monseñor y Ellacuría, y muchísimos otros y otras, historizaron la tradición cristiana fundamental y crearon un cauce, en el cual aquélla se ponía a producir. Cada uno de ellos y ellas, a su manera, retomó la antorcha que el otro dejó. Era difícil y costoso, pero también gozoso. Hicieron de la fe, del cristianismo y de la Iglesia algo real. Eso es lo que nos han dejado.

Sea cual fuere la historización adecuada para hoy, sea cual fuere la novedad y cambio de paradigmas, no se puede ignorar ese hecho mayor de la Iglesia salvadoreña. Como todas las iglesias cristianas, se deben remontar a la llamada de Jesús: "sígueme". Pero tiene el privilegio y la responsabilidad de caminar por el cauce que le dejaron los mejores, sus predecesores. $Y$ en cualquier caso, no puede desoír la llamada, que viene de los pobres, en forma de clamor poderoso y exigente. Una Iglesia y una fe así serán una Iglesia y una fe "reales".

\section{La gracia}

Cuarta proposición. La Iglesia necesita "gracia" para saber qué debe ser y qué debe hacer, y necesita "gracia" para hacer real ambas cosas. Para ello, debe tener fijos los ojos en Jesús.

27. Véase lo que escribimos en Jesucristo liberador, San Salvador, 1991, p. 134.

28. La formulación no es exacta, pues otros también prosiguieron la obra de Monseñor y el Padre Ellacuría ya llevaba varios años hablando, en el país. De todas formas, una trabajadora de la UCA, después de ver al Padre Ellacuría en televisión, dijo: "Desde que asesinaron a Monseñor Romero, nadie ha hablado así en el país". 


\section{1. "Con este pastor qué fácil es ser pueblo de Dios"29}

Para terminar las reflexiones de este artículo, digamos que Ellacuría vio en Monseñor Romero un don, tanto por lo que introducía de nuevo y de bueno en la historia, como por la fuerza que emanaba de él para que otros lo pusieran en práctica. Ellacuría vio a Monseñor como gracia para él y para el pueblo salvadoreño - aunque bien se podría decir que aquella Iglesia y aquel pueblo de la década de los setenta "se merecían" un buen pastor.

Así lo vio Ellacuría. En 1985, la UCA le concedió un doctorado póstumo honoris causa, y dijo estas palabras:

Ciertamente, Monseñor Romero pidió nuestra colaboración en múltiples ocasiones, y esto representa para nosotros un gran honor, por quien nos la pidió y por la causa por la que nos la pidió... Pero en todas estas colaboraciones, no hay duda de quién era el maestro y de quién era el auxiliar, de quién era el pastor que marca las directrices y de quién era el coadjutor, de quién era el profeta que desentrañaba el misterio y de quién era el seguidor, de quién era el animador y de quién era el animado, de quién era la voz y de quién era el $\mathrm{eco}^{30}$.

El contexto inmediato de estas palabras era la acusación de que la UCA habría manipulado a Monseñor - problema que, formulado de una u otra forma, persiste hasta el día de hoy, como si Dios y los pobres no hubiesen bastado para "manipular" a Monseñor Romero. Con las palabras citadas, Ellacuría quería aclarar la verdad y responder a la acusación. Pero además, quería dejar claro que Monseñor Romero fue líder, tal como él lo entendía: el que va delante y mueve a los demás con el ejemplo. Movía al seguimiento de Jesús, nada fácil en aquel tiempo, pues incluía riesgos, persecución y martirio.

Esto quedó más claro en las palabras con que prosiguió su discurso. "Completando lo que él solía decir 'con este pueblo qué fácil es ser buen pastor', puede decirse 'con este pastor qué fácil es ser pueblo de Dios'"'31. De esta forma gráfica, Ellacuría decía que Monseñor era gracia para el pueblo. Nosotros éramos unos agraciados.

$Y$ si se me permite una reflexión personal, pienso que Monseñor fue gracia para Ellacuría, de una manera muy especial. Muchas veces pensé que Ellacuría podía considerarse, más o menos, colega de Zubiri, en filosofía, y colega de Rahner, en teología, ambos insignes maestros suyos. Pero nunca se consideró colega de Monseñor Romero. Y la razón es que en Monseñor vio a alguien que siempre iba delante de él. Y eso ocurría en el modo como Monseñor Romero se

29. "La UCA ante el doctorado concedido a Monseñor Romero", ECA (1985) 168.

30. Ibid.

31. Ibid. 
puso ante el misterio de lo último, la fe en Dios. Como he escrito, sea cual fuere la fe del Padre Ellacuría, pienso que fue llevado en su fe -manteniendo el misterio de algo tan personal- por la fe de Monseñor Romero ${ }^{32}$. Dicho en otras palabras, vio en Monseñor a alguien que tenía fuerza para, sin imponer, "moverle" a él en la fe. Es la gracia.

\section{2. "Fijos los ojos en Jesús, el que inicia y consuma la fe" (Heb 12, 2)}

Jesús recibió, fue "agraciado", por la fe que veía en la gente sencilla, lo cual lo convierte en hermano nuestro, de lo cual, por cierto, no se avergüenza (Heb 2, 11). Pero el don y la gracia por excelencia es él: con él "vino la gracia y la verdad" (Jn 1, 17). Jesús es gracia como aparición inmerecida de lo humano y lo divino. Pero lo es también porque de él proviene la fuerza para ser nosotros humanos y deiformes.

Así lo dice la Carta a los Hebreos. Presenta a una comunidad en dificultades, que no debieron ser pequeñas: "no han resistido todavía hasta la muerte" (Heb 12, 4). En ese contexto, el autor les pone delante una larga lista de testigos de la fe, que culmina en Jesús "el que inicia y consuma la fe" (Heb 12, 2): Jesús es el "modelo" de creyente. Pero además, el autor añade dos veces (Heb 12, 2.3) que "tengan los ojos fijos en Jesús", pues de ese Jesús proviene la fuerza para su fe, para vivir como deben vivir y para superar las dificultades. "Fíjense en aquel que soportó tal contradicción, para que no desfallezcan faltos de ánimo" (Heb $12,3)$. Jesús es también "fuerza" para los creyentes. Caminando delante, mueve a que lo sigamos.

\section{$* * *$}

Terminamos volviendo a lo que decíamos en el título. En nuestros días, no se puede ocultar un "invierno eclesial" y una "marcha atrás" con respecto a Medellín. Es necesario recuperar una Iglesia evangélica, de los pobres. Y para ello es necesario poner a producir la herencia de Jesús. Su espíritu ilumina y anima. Y para ayudar a hacer presente hoy a ese Jesús, hemos ofrecido la vida, la fe y el amor de Monseñor Romero, vistos con el rigor y vigor con que lo presentaba el Padre Ellacuría.

32. Véase mi artículo "Monseñor Romero y la fe de Ignacio Ellacuría", en Jon Sobrino y Rolando Alvarado, Ignacio Ellacuría. "Aquella libertad esclarecida", San Salvador, 1999, pp. 11-26. 